\title{
7 \\ Realism and Anti-Realism in Young \\ Carnap
}

\author{
Johannes Friedl
}

The first part of this paper delves into the question of the basic tenets of Carnap's anti-metaphysics. Tying up to the accounts of authors like Michael Friedman and Werner Sauer, I examine the relation between verificationism and so-called logical criteria, arguing not only that verificationism is secondary, but that the integration of both instruments in Carnap's early philosophy faces difficulties. The second part focuses on the application of these instruments to the realism/idealism dispute. I try to show that Carnap's position is neither neutral nor stable, but (in different respects) involves concessions to both realism and idealism.

\subsection{Carnap Against Metaphysics}

The rejection of metaphysical questions is a constant in Carnap's thought. The most prominent application of this stance is to the debate on realism vs. idealism. Throughout his life, Carnap held that this debate, in its traditional form, is a mere pseudo-problem that cannot be answered simply because neither of the opposing positions can be stated in a meaningful way. As is well known, Carnap was not the

This work was supported by the Austrian Science Fund (FWF): P 30377-G24. Furthermore I am grateful to Gottfried Gabriel, Wolfgang Spohn, and Thomas Uebel for their comments on the talk on which this paper is based, to Ulf Höfer for comments on an earlier version, and especially to Christian Damböck, whose extensive critical comments forced me to reconsider (and at some points to rework) my argumentation.

\section{J. Friedl ( $\square)$}

Institut für Philosophie, Karl-Franzens-Universität Graz, Graz, Austria

E-Mail: johannes.friedl@uni-graz.at

C. Damböck, G. Wolters (eds.), Der junge Carnap in historischem Kontext:

1918-1935 / Young Carnap in an Historical Context: 1918-1935,

Veröffentlichungen des Instituts Wiener Kreis 30,

https://doi.org/10.1007/978-3-030-58251-7_7 
only one who took such a stance; this was common ground, at least during the heyday of the Vienna Circle. As Alberto Coffa puts it in his extensive study,

the view became a characteristically Viennese product in that it was widely accepted in

Vienna and widely regarded as absurd most everywhere else. (Coffa 1991, 223)

This view was made popular by Carnap's infamous Scheinprobleme in der Philosophie (below: Scheinprobleme) in 1928b, which obviously inspired a great many later writings within the movement. I limit myself to mentioning Schlick 1932 and second to none concerning the long-term broad effect - the first chapter of Ayer 1936. ${ }^{1}$ In this version, Carnap's attitude seems to be based entirely on the doctrine of verificationism. The dispute is to be rejected because it is neither a logical question nor an empirical one, which can be answered by reference to experience. As illustrated by Carnap's famous example of the two geographers (the one realist, the other idealist), this question is beyond all empirical evidence; the dispute is supposed to concern a matter of fact but, by the same token, has no concern whatsoever with detectable empirical data. For this reason, the whole debate is strictly meaningless.

The source of verificationism, at least in the Vienna Circle discussion, is Wittgenstein, as is unanimously acknowledged not only by Carnap himself but by various other members of it. ${ }^{2}$ However, let us take a closer look at the influence of Wittgenstein on Vienna anti-metaphysics as stated by Carnap in his intellectual autobiography:

\begin{abstract}
Another influential idea of Wittgenstein's was the insight that many philosophical sentences, especially in traditional metaphysics, are pseudo-sentences, devoid of cognitive content. I found Wittgenstein's view on this point close to the one I had previously developed under the influence of anti-metaphysical scientists and philosophers. I had recognized that many of these sentences and questions originate in a misuse of language and a violation of logic. Under the influence of Wittgenstein, this conception was strengthened and became more definite and more radical. (Carnap 1963, 25)
\end{abstract}

It is confirmed here quite bluntly that Carnap developed an anti-metaphysical argumentation already before he became acquainted with Wittgenstein's verification principle. I stick to the terminology suggested by Michael Friedman (1987, sec. IV) in calling Carnap's early anti-metaphysical instruments logical criteria. ${ }^{3}$ Therefore, in the first part of the present paper, the following questions must be dealt with:

\footnotetext{
${ }^{1}$ Of course, not even on this point there was complete agreement in the Circle and its periphery, as is indicated by the use of the limiting "widely" in Coffa. For a detailed survey, see Neuber (2018). ${ }^{2}$ See, for example, Carnap (1930/1959, 146, 1936/37, part I, 422). Actually, it is a matter of dispute if verificationism is expressed clearly in the Tractatus (on this, see Haller 1993, 95 ff.), but it is beyond question that in Vienna the Tractatus was interpreted in a verificationist manner; the interpretive problem is complicated by the fact that Wittgenstein, after his return to philosophy around 1928, definitely held quite radical verificationist ideas.

${ }^{3}$ Therefore I disagree with Mormann, who holds that the rejection of metaphysics in the Aufbau and in Scheinprobleme is based on epistemological (verificationist) reasons and is only later on (in Carnap 1930/1959, 1932a/1959) replaced by a sharper, logically inspired critique; cf. Mormann $(2000,67)$.
} 
- What exactly are these logical criteria? In what way are they incorporated into the central doctrines of young Carnap's philosophy?

- What is the relationship between the logical criteria and verificationism? Is there an internal relationship or are they simply two independent ways to attack, of which verificationism is the more radical? If the latter is the case, is this so because there are different kinds of metaphysical pseudo-sentences, each of which demands a different treatment (as hard-boiled positivists would put it: different diseases require different cures)?

In order to answer these questions, we must turn to Carnap's chief early work, Der logische Aufbau der Welt (1928a/2003, below: Aufbau). Published in the same year as Scheinprobleme, the basic ideas of this book stem from Carnap's pre-Vienna period. After presenting a first draft on the occasion of a visit to Vienna in January 1925, a first version, which is unfortunately lost, was submitted as Habilitationsschrift at the University of Vienna at the turn of the year 1925/26. ${ }^{4}$ The radical shortening of this version, surely a painful process that had to be done at the publishers' request, ${ }^{5}$ resulted in the publication in 1928. Note that (1) Carnap started to write the Aufbau only after getting feedback from the Circle when presenting the basic ideas, and that (2) the process of cutting the work down was not purely a matter of shortening. A multitude of discussions on the Aufbau with various members of the Circle took place after Carnap's move to Vienna in 1926. It is simply not a credible assumption that these discussions resulted in nothing on Carnap's side.

I took a short glance at the development of the Aufbau in order to clearly identify the exegetical problem we face: the Aufbau contains not only Carnap's early logical criteria, but also Vienna-style verificationism. We do not have a pure form of the logical criteria; verificationism is incorporated. On the other hand, Scheinprobleme is also not one-sidedly verificationist, as the popular reading would have it. To my mind, Werner Sauer (1992/93, $160 \mathrm{ff}$.) has convincingly argued for the essential role of the logical criteria in this booklet. We have to deal with two, as it were, contaminated versions; against this background, the mutual references between the two books are of little surprise. ${ }^{6}$

On the whole, however, it cannot be disputed that verificationism dominates the argumentation of Scheinprobleme, whereas logical criteria star in the Aufbau. Let us begin by taking a closer look at the Aufbau.

\footnotetext{
${ }^{4}$ Strictly speaking, he submitted only the first part as Habilitationsschrift; together with the second part (which followed a few weeks later), this first version had an extension of 566 typed pages. For an elaborated exposition of the origin of the Aufbau, see Damböck's paper in this volume.

${ }^{5}$ On this and the difficulties related to finding a publisher, see the correspondence Carnap-Schlick (Nachlass Schlick, Vienna Circle Archive, Haarlem; Nachlass Carnap, Archives of Scientific Philosophy, Pittsburgh).

${ }^{6} \S 178$ of the Aufbau refers to Scheinprobleme; a note in Scheinprobleme, p. 25, refers to the Aufbau (this note is omitted in the English translation).
} 


\subsubsection{Logical Criteria in the Aufbau}

A system of concepts is designed in the Aufbau. Here, we need to distinguish between the "theory of constitution" as the discipline which is concerned with the nature of systems of constitution, and the one constitutional system Carnap actually constructs in his book (as he himself admits, the construction is relatively sketchy in places). For his system, an autopsychological base is chosen instead of a physical or a general psychological one. ${ }^{7}$ I will come back to this, but one should make a note at the beginning that there is a plurality of possible systems distinguished by different chosen bases.

The aim of the enterprise is to provide a purely structural description of all concepts respectively all objects of knowledge. ${ }^{8}$ This target must be met because all content is subjective; only the restriction to pure structure secures the objectivity of language and science. However, there are obviously many different objects that can be characterized by one and the same structural description (e.g., " $X$ stands in a transitive relation to $\left.Y^{\prime \prime}\right)$. For this reason, a comprehensive system of all objects must be designed. In a sufficiently developed system, every object is unambiguously distinguished by a purely structural description, i.e., by relating it to the other objects. Carnap illustrates this by the example of a map of a railway network (§ 14).

The underlying demand for a purely structural description will not figure prominently in the following considerations; instead, I will focus on what is entailed by this: the demand for placing all objects unambiguously within a comprehensive system. This system is not ready-made, it has to be constructed. Starting from baseelements and base-relations, the construction ascends by creating classes and relations; so, stepwise, a type-theoretical hierarchy is in the making, wherein finally all objects find their exact place.

Against this background, how are metaphysical pseudo-sentences to be characterized?' Let's look at another passage from Carnap's autobiography, similar to the one quoted above, but a little bit more explicit concerning our present question:

Even in the pre-Vienna period, most of the controversies in traditional metaphysics appeared to me sterile und useless. [...] I also saw that the metaphysical argumentations often violated logic. Frege had pointed out an example of such a violation in the ontological proof for the existence of God. I found other examples in certain kinds of logical confusion, among them those which I labelled "mixing of spheres" ("Sphärenvermengung") in the Logischer Aufbau, that is, the neglect of distinctions in the logical types of various kinds of concepts. (Carnap 1963, 44 f.)

\footnotetext{
${ }^{7}$ Aufbau, $\S$ 62-64; just before the publication, Carnap planned to write another book in which a constitutional system on a physical base should be developed.

${ }^{8}$ For Carnap it makes no logical difference whether concepts or objects are spoken of; cf. Aufbau, $\S 5$.

${ }^{9}$ In the English translation of the Aufbau, the expression "pseudo sentence" is introduced in $\S 180$. It is noteworthy that the German original does not contain the corresponding expression "Scheinsatz", but this is unambiguously and exactly what is meant by "Wortreihe [...], die den äußeren Bau eines Satzes hat und daher für einen Satz gehalten wird, ohne einer zu sein" (ibid.).
} 
According to this, a metaphysical pseudo-sentence is created in the following way: in regular use, a word stands for a concept precisely distinguished within the constitutional system. Misuse arises when this word is plucked out of this context and used in another context - another sphere of the system. In this new sphere, there is simply nothing that the word stands for; it has no defined place and corresponds to no defined concept as in the original sphere. In ordinary language, there is a constant risk of such misuse, especially due to the many ambiguous words it contains. In contrast, in the logical language of the constructional system it is sufficient to pay attention to the logical type of the signs to recognize whether a sentence is a pseudosentence or a genuine one.

In summary, the core thesis of the Aufbau is the following: only pure structure is objective, and therefore all concepts must be described in a purely structural manner. To meet this target, a constitutional system must be built up to a sufficient degree, thereby obtaining as many relations as are needed for unambiguous characterization. The constitution proceeds by building classes and relations, thereby creating, stepwise, a hierarchic system. Objective meaning is nothing over and above the unique place within the system. Therefore a word loses its sense when it is detached from that defined place and used in a different sphere. Additionally, there is no essential difference to the case where a word lacks meaning from the start - to this, and therefore to the justification of speaking of logical criteria (in the plural), I will return later.

Thus we see: logical criteria are a straightforward consequence derived from the core thesis of the Aufbau, the restriction to pure structure.

\subsubsection{Verificationism in the Aufbau}

Beside the logical criteria, which are self-sufficient, the Aufbau also contains passages in which the rejection of metaphysical pseudo-sentences seems to be grounded on verificationism. It cannot be proven in a strict sense that these passages are the result of the Viennese influence, but in addition to the above-mentioned attributions as to the origin of the verification principle, it is noteworthy that the concept of verification is only mentioned in the later parts of the book. The most striking passage appears in $\S 179$ :

From a logical point of view, however, statements which are made about an object become statements in the strictest scientific sense only after the object has been constructed, beginning from the basic objects. For, only the construction formula of the object - as a rule of translation of statements about it into statements about the basic objects, namely, about relations between elementary experiences - gives a verifiable meaning to such statements, for verification means testing on the basis of experiences.

Apart from the question of their temporal relationship, what is the logical relationship between these two criteria? Presumably Carnap himself thought (at least for a certain time) that the rejection of metaphysical pseudo-sentences by means of the verification principle and by application of the logical criteria are but two sides of 
the same coin. That Carnap at least tended to treat these two instruments as equivalent comes out especially clearly in "The Elimination of Metaphysics through Logical Analysis of Language" (Carnap 1932a/1959). As he puts it in this paper, a word has meaning only if the way of its appearance in the simplest kind of sentence ("elementary sentence") is known and if for such a simple sentence $S$ an answer is

given to the following question, which can be formulated in various ways:

(1) What sentences is $S$ deducible from, and what sentences are deducible from $S$ ?

(2) Under what conditions is $S$ supposed to be true, and under what conditions false?

(3) How is $S$ to be verified?

(4) What is the meaning of $S$ ? (Carnap 1932a/1959, 62)

That's a well-known and much objected passage. Usually the equation of (1.) and (2.) is rejected; in the present context, our focus is on the equation of (1.) and (3.). According to Carnap, the former formulation (clearly echoing the constitutional definitions of the Aufbau) is the "proper" formulation, the latter one the mode of speech of epistemology. Although the Aufbau contains no such explicit equation, in certain respects the constitutional system is developed as if it were meant to incorporate verificationism.

In the first place, the aim of the Aufbau is the construction of a hierarchy of concepts; however, the basic units are sentences, not concepts, since only sentences can be properly assigned a meaning. Concepts are only defined contextually as parts of sentences, not as isolated items. That is of importance for our question because there is of course no sense in speaking of verifying concepts. Strictly speaking, the object of verification is the question of whether a specific concept is "realized". Regardless of alternative or more accurate formulations, only sentence-like, propositionally structured items are possible objects of verification.

Second, constitution proceeds by translation. A concept can thus be constituted if all sentences in which it occurs are translatable into sentences without that very concept. What has to remain constant in the translation is the logical value (as contrasted with the epistemological value), a claim that is related to the thesis of extensionality ( $(50)$. Crucially, in this sense the meaning of a sentence cannot transcend the meaning of those sentences by which it is constituted. Indeed, that is one of the central points of verificationism (in its original, strong version): the meaning of a sentence is completely exhausted by that which is verifiable.

The most important feature is the third one: the constitutional system of the Aufbau is erected on an autopsychological base. In contrast to other possible bases, Carnap chose this base to mirror the epistemological order. When ascending the constitutional hierarchy step by step, we start from what is epistemologically prior. For example, sentences about physical objects are not only translatable into sentences about sensory qualities, but knowledge of physical objects has to be mediated by sensory qualities, whereas the

recognition of our own psychological processes does not need to be mediated through the recognition of physical objects, but takes place directly. (Aufbau, § 58) 
This "methodological solipsism"10 reflects a basic tenet of verificationism. It is a fundamental requirement of verification that there is not only logical equivalence (respectively symmetry, second point), but also epistemological asymmetry. Purely logical relations cannot by themselves be sufficient for verification; if the base is not epistemologically prior in some sense, the whole endeavor of verification is pointless. ${ }^{11}$

\subsubsection{The Disharmony of Verificationism and Logical Criteria}

We can thus see that, on the whole, logical criteria and verificationism make a perfect match, don't they? My thesis is that, contrary to this appearance, verificationism, only adopted later, is fundamentally at odds with a central idea of the Aufbau. I start by examining the last point mentioned, the problem of the base.

\subsubsection{The Problem of the Base}

Logical criteria are valid for all constitutional systems regardless of the (arbitrary) chosen base; in contrast, verificationism is valid solely for systems with an autopsychological base. So far, there is no problem, simply because, to mirror the epistemological order, Carnap chose such a base. Upon closer examination, however, a deep problem is revealed. The epistemological priority of the base, which is presupposed by verificationism, conflicts with the Aufbau's attempt to secure intersubjectivity. Remember Carnap's solution to this problem: the restriction to pure structure. Obviously the starting point cannot consist in private, subjectively "given" experiences. To be more precise, the problem of the base splits into two parts: the selection of basic relations and that of the basic elements themselves. It is only the former which can be said to be the real base in that they are undefined and all other concepts are defined by them $(\S 61)$. The basic elements are at the beginning completely "unanalyzable units"; they have no features that can be described. Nevertheless, to get the process of constitution started, it is necessary to speak of these elements. The solution to this problem is the ingenious introduction of "quasi-analysis". I will not go into details but confine the argument to the (supposed) performance of this kind of analysis ("a synthesis which wears the linguistic garb of an analysis", § 74). By this procedure we are able, so to speak, to analyze the unanalyzable. As a result, the

\footnotetext{
${ }^{10}$ Aufbau, § 64; primarily due to the criticisms of Neurath (e.g., Neurath 1931/1959, 290), Carnap finally dropped this term, although he insisted that nothing else was ever meant than the rather trivial fact that in the process of verifying (or testing), one finally has to refer to one's own observations (Carnap 1936/37, part I, 423 f.).

${ }^{11}$ Note that here we are dealing with the Aufbau. Later on, Carnap abandoned both of these two features of verificationism (strong verification, autopsychological base); see below.
} 
basic elements, which cannot be said to have any properties at the beginning, become elements within the constitutional system about which can be spoken.

The gist of the matter (as far as we are concerned with here) is this: it is potentially misleading to speak of an autopsychological base. At the beginning, there is not even meaning in speaking of a self (as opposed to others) or of a psychological realm (as opposed to a physical realm). This talk makes sense only after these concepts have been constituted themselves by the process of quasi-analysis. And it is only because of this result - and not because of the initial choice - that we are entitled to speak of constitutional systems with a certain kind of base:

In our system form, the basic elements are to be called experiences of the self after the construction has been carried out; hence, we say: in our constructional system, my "experiences" are the basic elements. (Aufbau, § 65)

This is not a peculiar feature of the basic concepts; it is simply a central thesis of the constitutional theory that a concept is a concept qua being constructed, qua being placed within the system:

[...] in fact, the constructed objects are objects of conceptual knowledge only qua logical forms which are generated in a certain way. Ultimately, this holds also for the basic elements of the constructional system. [...] It is only through this procedure, that is, only as constructed objects, that they become objects of cognition in the proper sense of the word, in particular, objects of psychology. (Aufbau, § 177)

Thus the idea of the essentially constitutional nature of "my experience" and the idea of verification are not on a par. What is primary, in the constitutional sense, are basic relations and basic elements, but the latter are completely without properties at the beginning. The choice of a base is a choice made for some logical construction or other, and no more than this. Epistemological priority of any kind is not provided for within the system; in contrast, what is epistemologically prior (my experiences) is to be found in the constitutional system only at a higher level. To sum up: the epistemological priority needed for verificationism cannot be expressed in the constitutional system, which bans talk of any objects that are not constituted.

\subsubsection{Different Cures for Different Diseases?}

Even if it is admitted that verificationism cannot be integrated into the Aufbau offhand, one might hold on to the idea that verificationism is needed in order to complete the anti-metaphysical argumentation. Might it not be the case that there are in fact at least two different kinds of pseudo-sentences? On this reading, it was necessary for Carnap, radicalizing his anti-metaphysical attitude in Vienna, to supplement his early logical criteria by verificationism. In doing so, he may have been mistaken in viewing verificationism simply as the other side of the coin, but what harm is there? This is the view according to which different kinds of pseudo-sentences all demand a different treatment.

There are several passages in Carnap's early writings that favor such an interpretation, i.e., an interpretation characterizing pseudo-sentences in two different ways: 
A string of words can fail to be a sentence in two ways: first, if it contains a word which has no meaning, or, second (and this is the more frequent case), if the individual words do indeed have meaning (i.e., if they can occur as parts of genuine, not merely apparent, sentences), but if this meaning does not fit with the context of the sentence. ${ }^{12}$

The first case - a word without meaning - would be a case for verificationism, whereas the second case is a transgression of the spheres in which the different concepts are located. The latter case, a violation of the logical grammar of language, would be a case for logical criteria.

The first problem for such an interpretation is that it fits in badly with other passages from the same time. Remember the passage from Carnap 1932a/1959 quoted above (7.1.2), where Carnap explicitly speaks of one and the same question presented in different clothes.

A closer look reveals that the supposed difference between the two cases vanishes. In both cases, the essential feature is the lack of determination within the system. In the second case, a word which in regular use designates a concept is detached from this connection; therefore there is no longer a corresponding concept, i.e., the word has lost its connection to the specific place in the system. On the other hand, to designate no place within the system is simply to lack meaning. The first case differs only insofar as there is not even another legitimate use of the word. The mistake that is made here is more radical insofar as from the start no determinate place within the system is defined, and as a result there is no mixture of spheres. The result in both cases, however, is the same: a lack of meaning because of the failure to specify a unique, determined place within the system. ${ }^{13}$

\subsubsection{Verificationism and Logical Criteria in Carnap's Development}

Up to now, I have argued not only for the temporal priority of the logical criteria, which can hardly be disputed, but also for a logical priority. Verificationism is only secondary in Carnap's thought. ${ }^{14}$ Carnap's anti-metaphysical attitude is not affected by the rise (and fall, most philosophers today would add) of verificationism. Let's take a look at Carnap's further development, especially at the role assigned to verificationism in his later writings. Here's a passage from "Testability and Meaning":

It seems to me that it is preferable to formulate the principle of empiricism not in the form of an assertion - "all knowledge is empirical" or "all synthetic sentences that we can know are based on (or connected with) experiences" or the like - but rather in the form of a proposal or requirement. As empiricists, we require the language of science to be restricted in a certain way; we require that descriptive predicates and hence synthetic sentences are not

\footnotetext{
${ }^{12}$ Aufbau, § 180; this disjunctive characterization is also to be found in Carnap (1932a/1959, sections 2 and 4).

${ }^{13}$ Cf. Sauer $(1992 / 93,167)$.

${ }^{14}$ I want to emphasize once more that this was stated long ago by Friedman (1987, sec. IV), Sauer (1992/93), and Richardson (1992, 1998, 25-28). I am especially indebted to Werner Sauer and a talk he gave in Graz in spring 2016.
} 
to be admitted unless they have some connection with possible observations, a connection which has to be characterized in a suitable way. (Carnap 1936/37, part II, 33)

The history of verificationism within the Logical Empiricists' movement is usually told as a history of liberalization. This is not incorrect, of course. Carnap himself moved on from the requirement of complete definability to confirmability in different shades. And it is no easy task to specify the "suitable way" in which theory has to be connected with experience, or, to put it in Carnap's terms, to specify the relations between a theoretical language and an observational one. ${ }^{15}$ The second important feature of verificationism - as it was conceived in the Aufbau - was the autopsychological base. Here, too, the conception changed dramatically by Carnap's turn to physicalism, connected with the new conception that the question of the nature of the base (the form of the protocol-sentences) is not a theoretical question at all, but a matter to be fixed by convention. ${ }^{16}$

What is more interesting in the present context is the status of the verification principle itself. If it is nothing but a proposal, every metaphysician can relax. In Carnap's mind, however, the metaphysician does not gain anything by this. At the bottom of Carnap's anti-metaphysics always lie what I've called logical criteria. To be sure, the argumentation changed its outward appearance over the years, from the Aufbau to "Empiricism, Semantics and Ontology" (Carnap 1950). In that famous paper, the weight is carried by the full-blown distinction between internal and external questions. We have just seen that the basic idea behind this distinction is already at work in the Aufbau, by locating the metaphysician's fundamental mistake in the attempt to use concepts not determined within the system. It is not in the scope of this paper to reconstruct the exact development of this "iron string". ${ }^{17}$ The time has come to turn to the application of the Aufbau-style logical criteria to what has always been thought of as a prime example of a metaphysical dispute: the question of realism.

\subsection{Realism and Anti-Realism in the Aufbau}

\subsubsection{Constitutional and Metaphysical Reality}

Of course, the concept of the "real" is not to be banished altogether. So, what do we mean when we ascribe reality to an object in a meaningful way? According to what has been said in the first part of this paper, it is clear that there is a precondition that must be fulfilled: the object has to be constituted. If the concept (or the object) were not a constituted one, we simply would not know what we are talking about. If we want to know if there is at least one mountain in Africa which is higher than $5000 \mathrm{~m}$,

\footnotetext{
${ }^{15}$ For his final position on this, see Carnap (1956).

${ }^{16}$ For the first time expressed in Carnap (1932c).

${ }^{17}$ Friedman speaks of "deep continuities" in Carnap's rejection of metaphysics (Friedman 2007,

152). This continuity is shown in detail in Sauer (1992/93).
} 
it is a prerequisite that the concept "a mountain higher than $5000 \mathrm{~m}$ " is already constituted as an object belonging to the sphere of physical things. This task of constitution is the first task of science in a logical sense (in the actual process of scientific development, concepts are taken from everyday knowledge and only afterwards and gradually rationalized). While it is a matter of convention which features are used in the constitutional definition, it is essential that a unique determination can be reached. After this task is accomplished, all other questions about the concept (or the object) are of an empirical nature. ${ }^{18}$

The decision as to the reality of a constituted object is a subordinate, empirical one. To be a little more precise, the question of the object's reality is located at a relatively high level of a constitutional system implemented sufficiently far. The difference between real und unreal objects is the difference between their exact places in the comprehensive system. The real mountain is to be included in the system in a way in which the unreal mountain is not (e.g., the real mountain can be climbed, has a certain mass etc.), that is, it can be integrated within the system of perceptions and law-like relations connecting them. The unreal mountain is located in a different place within the system and is constituted as a hallucinated or dreamed mountain.

The given suggestions will suffice to make it clear that the difference between reality and nonreality (dream, invention, etc.) retains its full meaning even in a constructional system which is based upon an autopsychological basis, and that this distinction in no way presupposes any transcendency. (Aufbau, § 170)

"Reality" designates a subsystem of the constitutional system. This subsystem contains all objects which are accepted by the special sciences. The criteria by which this subsystem is distinguished are altogether scientific criteria. The various scientific disciplines are connected from the outset, their fields being parts of the one comprehensive constitutional system.

It is crucial to see that this concept of reality depends solely on distinctions within the constitutional system; the difference between the real and the unreal is completely internal. This constitutional concept must be sharply distinguished from the metaphysical concept of reality. The latter conception does not depend on differentiations within the constitutional system; according to it, reality must be assigned to objects outside any system and independently of it. The difference between the two conceptions is illustrated by the following example, which is very similar to the example of the two geographers from Scheinprobleme:

The difference between the two meanings becomes clear through the following two questions: "Was the Trojan War a real event or merely an invention?" and "Are those objects which are not feigned or simulated, for example the perceived physical bodies, real, or are they merely contents of consciousness?" The first question is treated by historical science; it is to be resolved with empirical and constructional methods, and hence there is no divergence of opinion among the adherents of the various philosophical schools. The second

\footnotetext{
${ }^{18}$ This is a point of departure from the Neo-Kantianism of the Marburg school: constitutional theory holds that a finite number of characteristics is sufficient for unique determination, whereas the Marburg school holds that determination of an object can never be accomplished; cf. Aufbau, $\S 179$.
} 
question is customarily transacted within the field of philosophy; it is answered in different ways by different schools; we shall see later that it is extraconstructional and hence extrascientific; it is metaphysical. (Aufbau, § 175)

There are thus two versions of realism, a constitutional one and a metaphysical one. According to Carnap, there is total agreement with everything that constitutional realism asserts ( $(177)$ : there is a difference between real und unreal objects; objects are intersubjective; objects exist independently of me insofar as their behaviour does not depend on my volitions (except in those cases where there is a causal connection); objects are subject to the laws of nature. Thus, constitutional theory and constitutional realism are in total agreement.

The same is true of idealism: like realism, idealism comes in two versions. Constitutional theory and (good) idealism agree that all objects of knowledge must be constituted, i.e., must be "built" by logical operations starting from a base.

In contrast to the constitutional notions of realism and idealism, the concept of a metaphysical reality cannot be constituted within any constitutional system. If it cannot, however, it is no concept at all but a meaningless word since meaning is simply the logical place within. Additionally, there is of course no sense in ascribing reality to the whole constitutional system - a concept that distinguishes nothing is not a concept; differences must be differences within the system. The realist's mistake consists in detaching the word from the context in which it has sense and applying it where it doesn't have sense and cannot be redefined. Therefore the question of metaphysical realism is nothing but a prime example of a violation of our so-called logical criteria: sense is lacking because of the failure to specify a logical place within the system.

One of the strengths of Carnap's position seems to be that it takes into account an old principle, according to which there is no concept without differentiation. If nothing is excluded by applying a concept, then in fact nothing is attributed. Surely, from a ("metaphysical") realist point of view, the concept of constitutional reality would appear to be inadequate in itself, yet it is very difficult to define precisely what is omitted by this conception. Carnap is realist, however, in that he ascribes the same kind of reality to objects of experience and to theoretical entities like electrons (insofar as the latter is an accepted scientific concept). It would be a gross mistake to read him as a kind of instrumentalist. Instrumentalism depends on the distinction between objects whose reality is guaranteed in some way (mostly by experience) and those concepts which are only a means for ordering these "real" items. The difference between real and unreal within the constitutional system is not the difference between a rock-solid base and the lofty construction raised on it - the former, too, is rationally accessible only as a constituted object. The difference is not one of intrinsic, but of relational character: being a relatum of law-like connections accepted by science, or not. ${ }^{19}$ Another important aspect for placing Carnap's theory within great debates has already been mentioned above, when reporting his view

\footnotetext{
${ }^{19}$ For the difficulties and dangers in applying the distinction realism/instrumentalism to the work of Carnap, see also Parrini (1994).
} 
that all questions divide into constitutional (i.e., logical, albeit involving conventional) ones and empirical ones. These two components are exhaustive: "there is no synthetic a priori" (Aufbau, § 179). Questions of existence presuppose constitutional theory to be meaningful, yet are answerable only by empirical investigations. By tying all claims of existence to experience, Carnap's overall view is ultimately bound to the empiricist tradition. ${ }^{20}$

Carnap emphasizes over and over again the neutrality of constitutional theory in regard to the traditional realism/idealism dispute. It is indeed easy to see that the legitimate versions of realism and idealism (the constitutional ones) do not contradict each other; they go perfectly well together. Realism and idealism contradict each other only in the metaphysical sense - properly speaking, they only seem to contradict each other because neither metaphysical position is expressible in a meaningful way. However, this neutrality is problematic. In the remainder of this paper, I discuss two objections, the first pushing the Aufbau in the direction of metaphysical realism and the other in the direction of metaphysical idealism, thus trying to show an inherent instability of Carnap's position.

\subsubsection{Does Constitutional Realism Presuppose Metaphysical Realism?}

The first passage in which the Aufbau touches on the realism/idealism problem is to be found very early, in one of the first paragraphs:

Does thinking "create" the objects, as the Neo-Kantian Marburg school teaches, or does thinking "merely apprehend" them, as realism asserts? (Aufbau, § 5)

As Carnap later tries to make clear ( $\S 95 \mathrm{ff}$.), this question concerns only the possible modes of speech. The proper language which is used in the Aufbau is the language of symbolic logic. Both realistic and idealistic languages are merely auxiliary means employed for the purpose of illustration. ${ }^{21}$ The realistic language mainly serves to make the adequacy of the constituted concepts more visible. The sciences use realistic language, and a constitutional system is not completely free-floating the aim is the reconstruction of concepts already in use. Using realistic language merely makes it easier to see if the reconstruction was successful, i.e., if a constituted concept is an adequate reconstruction of a concept already in use. The use of idealistic language serves another purpose. Its use makes it more readily visible that the constitution of a concept, starting from the base of the system, is flawless. The ideal-

\footnotetext{
${ }^{20} \mathrm{I}$ admit that this is not very exciting, but nonetheless it seems noteworthy to me. When criticizing (rightly, in my mind) the received interpretation of the Aufbau as the attempt of reducing all concepts to the "given" and thereby as the most elaborated version of a reductive empiricist project, this very basic commitment to empiricism should not be overlooked.

${ }^{21} \mathrm{~A}$ fourth language that is used in the Aufbau can be neglected here because this language is simply the translation of the language of symbolic logic into ordinary language.
} 
istic language is the language of the operations that must be executed within the hierarchy of the constitutional system up to the point when the concept in question is ultimately reached. Thus its use does not involve any assumptions about psychological processes; it only formulates the operational rules which can be applied by anyone, "be it Kant's transcendental subject or a computing machine" (Carnap 1963, 18).

We have to do here with another dimension of the issue of realism. There is no third conception of realism (or idealism) beside the (good) constitutional concept and the (bad) metaphysical concept. Here we are dealing only with the language of constitution itself, and the results above are not touched upon. Even in a constitutional system that uses exclusively idealistic language, there is no sense in speaking of metaphysical idealism. On the other hand, the justified preference for realistic language by scientists and laymen is of no concern for the philosophical problem of realism (Aufbau, $\S 52$ and 178); even in a constitutional system with realistic language, there is no place to be found for metaphysical realism. So, no matter what mode of speech is chosen, only constitutional realism/idealism makes sense.

Our current concern is with the realistic language. It can be agreed that merely talking in this manner does not represent a commitment to metaphysical realism. What is highly dubious is the purpose of this talk: the use of realistic language should facilitate the recognition of the agreement of purely structurally defined concepts with those already in use. One now wonders how this kind of recognition can be achieved. It is clearly not a comparison that can be made within the constitutional system, simply because one constituent of the relation is outside of it. Either it is conceded that the comparison cannot be made (in contrast to Carnap himself, who says that this comparison is facilitated by the use of realistic language) or we admit that there is more about knowledge than the official statement of the Aufbau admits. According to this official definition ( $§ 178$ ), epistemology is restricted to the relations between the different spheres of a constitutional system. Rejecting this definition amounts to taking literally Carnap's speech of "familiar" ("bekannte") concepts (Aufbau, especially § 98) which are to be reconstructed; by this we are admitting the existence of a kind of knowledge that is in some sense different, but nevertheless genuine knowledge - thereby contradicting the claim that the constitutional system is a comprehensive system including all objects of knowledge.

The problem, so far, is essentially of the same kind as the one we touched upon in the first section. There we encountered the difficulty that the epistemological priority of the base needed for verification cannot be accounted for in the constitutional system. Now, the same is true for the supposed recognition of the agreement of constituted concepts with non-structural ones - but that is not the end of the story.

A deeper problem is lurking in all of this. What makes the constitutional system of the Aufbau a reconstruction of empirical knowledge dealing with reality? Obviously this question cannot be answered by trying to tie up the constitutional system to reality: constitutional reality is not something external to the system but a subclass of it - and therefore by trying to answer the question in this way, one is inevitably led to metaphysical reality. Nonetheless, it seems to me that this is what Carnap is doing - albeit implicitly and in a concealed manner. Remember how the constitutional concept of reality is introduced in the Aufbau: the criteria which distinguish real from unreal objects are altogether scientific criteria; real objects fit in the net of law-like 
connections stated by science in a way that unreal objects do not. The constitutional system determines what is meaningful, not what is real; for the latter purpose, we need help from the sciences. ${ }^{22}$ Clearly the real sciences are meant to do this work, not any purely invented science. A purely fictional science (as presented in some science fiction novels) would draw a completely different line between the real and the unreal. How, then, can the difference be established between real science and fictional science, since both consist of objects and law-like relations that are expressible within the constitutional system? Why are the objects and laws of the one designated real (in the constitutional sense) and those of the other unreal? At this point Carnap seems to make reference to the one existing real science, but this only leads us back to metaphysical reality and thus nothing is gained by that move. It is surely a purely metaphysical gesture when the attempt is made to secure the contact of the constitutional system to reality by tying it up to (metaphysically) real facts. In the same way, however, it is also in the domain of the metaphysical to draw the line within the constitutional system between real and unreal by the help of a (hidden) reference to the one existing real science. Ultimately, it is a (metaphysical) fact that a specific scientific system holds sway at a given period in time, like the (metaphysical) fact that, e.g., there is at least one mountain in Africa which is higher than $5000 \mathrm{~m}$.

To sum up: either the concept of constitutional reality is determined by the help of metaphysical reality, or the determination of constitutional reality is arbitrary in a way that leaves one completely at a loss when asked what it is that is defined.

This seems to be a very naive objection, but consideration of subsequent controversies substantiates my point, especially the discussion between Carnap and Edgar Zilsel only a few years later. Zilsel asked for the connection of purely structural systems to the one reality, respectively for the distinction of the one real science (in contrast to other possible systems of sentences; Zilsel 1932/33). For Zilsel, this can only be accomplished by admitting an "ineffable" substrate of structures, which is to be found in the content of experiences. ${ }^{23}$ While rejecting any talk of the "ineffable", and therefore Zilsel's answer, Carnap acknowledged his question. Real science, so his own answer, is distinguished by the historical fact that it is the science that is held by the scientists of our cultural circle (Carnap 1932b, $179 \mathrm{f}$.).

Of course this will not do. In my opinion, there is hardly anything to add to A. J. Ayers' $(1982,174)$ comment: as he puts it, any system of sentences may include a sentence asserting that this is the system that is held by the scientists of our cultural circle, so nothing is gained by this move. ${ }^{24}$ What is meant is that it is in fact the one accepted system, or in other words, that it is real; however, it is exactly this position that is not allowed according to the Aufbau.

\footnotetext{
${ }^{22}$ Here I simplify a little. Scientific results are in fact already used in the process of ascending the stages of the system, and not only subsequently when the system has been completed. For the point in question, however, it does not matter at what stage scientific results are used.

${ }^{23}$ In this respect, Zilsel's position is close to the one Schlick held at least for a certain time; cf. Schlick (1938/2012).

${ }^{24}$ This objection was made first (and at greater length) in Ayer (1936/37, 233 f.).
} 
Is there no way out for Carnap? When looking at another of Carnap's papers from the time of the Aufbau, "Eigentliche und uneigentliche Begriffe" (Carnap 1927), ${ }^{25}$ the following rejoinder is obvious: the objection depends on a mix-up of constitutional definitions with implicit definitions. Only concepts of the latter kind are "free-floating" and need to be connected to reality afterwards. In contrast, the constitutionally defined concepts have this contact to reality from the beginning, being defined stepwise from a base. ${ }^{26} \mathrm{We}$ are thus back at the problem of the base, this time concerned, not with epistemological priority, but with the question of contact with reality.

It is at this point that a number of authors see the major failure of the project of the Aufbau (not only with respect to the problem of reality, with which we are concerned here). Since I have nothing to add to the various writings where this is discussed in considerable detail, ${ }^{27}$ I will confine myself to a short (and simplifying) abstract:

The project of the Aufbau is the characterization of all concepts as purely structural. As already stated in section 7.1.3.1, the proper base for the constitution is a relation (and not the elements between which this relation holds), but what about this basic relation itself (the "Recollection of Similarity", § 52)? A dilemma now occurs: either this basic relation is not purely structural or it is. In the first case, all other concepts, which are defined by it, are also not purely structural and the goal of the Aufbau is doomed to fail from the beginning. In the second case, this basic relation can be defined in purely logical terms. ${ }^{28}$ What this means is that the whole constitutional system contains only expressions of logic. Now, however,

in Carnap's hands, empirical science achieves objectivity by, in the end, severing its ties to empirical reality in just the way mathematics and logic do. (Richardson 1998, 37)

And this, of course, is as little a solution to our problem as the killing of a sick person is a cure.

\subsubsection{The Constitutional Concept of Reality and Metaphysical Idealism}

The objection just made was pushing in the direction of metaphysical realism, which seems to be presupposed but of course cannot be acknowledged. A second possible objection arises by pushing in the other direction and examining the question whether the constitutional concept of reality is not in fact "idealism in disguise" (Parrini 1994, 260).

\footnotetext{
${ }^{25}$ For the context of this paper (Schlick's equation of implicit definitions with the Aufbau's structure statements), see Friedl (2013, chap. I, sec. 3).

${ }^{26} \mathrm{Cf}$. Carnap (1927, especially $355-358$ and $372 \mathrm{f}$.).

${ }^{27}$ The first (and in my mind best) discussion is that of Friedman (1987); cf. also Richardson (1998, chap. 2) and Soames (2018, chap. 6).

${ }^{28}$ Carnap goes so far as to suggest taking this basic relation itself as a concept of pure logic; cf. Aufbau, §§ 153-155.
} 
As said above, according to Carnap, the only legitimate use of "reality" is a separation within the system; the real objects are distinguished from unreal objects by law-like connections. These laws naturally originate from empirical science, so the criteria by which the line is drawn between real and unreal objects within the constitutional system are exclusively scientific criteria. In which sense is "criteria" to be understood here? In one sense of this term, there is no harm in what has been said thus far: Of course the criteria of what we take to be real must stem from empirical science (which is meant here to include perception; the rationalist position is neglected for the moment). We cannot know in advance that there is no such thing as Pegasus, and so on. All of that is nothing more than the old and basic empiricist position, according to which knowledge of existence depends on experience (respectively empirical science); however, this is not the sense in which this word is used by Carnap here. He takes criteria in a definitional sense, so the result is: "real" is whatever is acknowledged as real by the sciences. The difference between the two uses can be stated in the following way: according to the (harmless) first proposition, science is the only way to gain knowledge of reality. According to the second, science defines (or constitutes) what is real. This second claim is far from harmless. In our pre-theoretical everyday realism, we believe that well-established scientific theories present a reason to believe that reality corresponds to the way it is presented in the theories. Now, the relationship between science and reality is turned upside down: since reality is defined by science, it becomes a matter of necessity that reality corresponds to this definition. Now it no longer makes sense to deny the reality of what is acknowledged as real by the sciences - contrary to our (historical) knowledge that science has erred sometimes, and contrary to the view that, in principle, a scientific theory is never immune to being dropped.

The case of a theory change is especially striking. By holding the view that meaningful talk of reality is completely exhausted by scientific criteria, one is forced to admit that reality itself changes when a new scientific theory for a specific domain is adopted. Alternatively, if one does not want to accept a change of reality as a result of a theory change, one has to admit a multitude of realities - members of different scientific communities live in different worlds, to put it in Kuhnian terms.

To sum up, talk of reality makes sense for Carnap only if this concept is constituted within the system. The constitution is achieved by scientific criteria. Therefore, (at least some) scientific laws change their character and are no longer to be taken in a descriptive sense, but have become prescriptive. In this sense, what is real depends on scientific laws, on what we think - and that is the core of idealism. 


\subsection{Concluding Remarks}

By pushing Carnap in the direction of metaphysical realism as well as in the direction of metaphysical idealism, we are confronted with the deep Kantian roots of Carnap's thought ${ }^{29}$; far be it from me to deny this background. It seems to me, however, that when (correctly) emphasizing this background it not often highlighted that the Kantian heritage includes Kantian problems, such as the notorious thing-initself and the reconciliation of (transcendental) idealism and (empirical) realism. A secondary objective of my paper was to show the reappearance of these Kantian problems in Carnapian clothes. Concerning the near future (seen from 1928), it is interesting to see that almost all of the issues of the soon-to-get-started protocolsentence debate are - at least in nuce - already present in unfolding the Aufbau's treatment of realism. We had to speak about the problem of the base both with regard to epistemic priority as well as with regard to the question of contact with reality; intersubjectivity is the reason for the demand for a purely structural description (this "structural account" is replaced by physicalism at the beginning of the 1930's). ${ }^{30}$ Even the third big issue in this debate - the nature of truth - is lurking throughout. ${ }^{31}$ All I can do here, however, is indicate one way into this inexhaustible debate. ${ }^{32}$

More important than this historical embedding is the question of how to assess the critical arguments given here (insofar as they are sound, of course) in contrast to the strengths of Carnap's analysis - that there is something to be said in favour of it is a point I already highlighted before raising the misgivings.

It is the Aufbau's claim to give a rational (purely structural) reconstruction of concepts already in use. I think that this claim can be confidently rejected: Carnap's analysis of the concept of reality does not deliver an adequate result. However, the question of whether the whole of our vague, pre-theoretical views concerning reality can be captured by a philosophical analysis at all is an open issue. The standpoint of my criticism is clearly a realistic one, but I did not try to explicate this underlying concept of realism. Carnap himself tries to cash out several conceptions of such an "absolute" reality, concluding that any attempt to do so would result in a "nonrational, metaphysical concept" ( $\$ 176)$. Now, this passage is not a piece of rigorous reasoning in the context of drawing such a strong conclusion from an undetermined

\footnotetext{
${ }^{29}$ The Kantian roots of Carnap's concept of constitutional reality are pointed out by Parrini (1994, note 4,274 f.).

${ }^{30}$ On this transition, see Sauer (1989).

${ }^{31}$ This is obvious by the fact that the discussion about truth in the protocol-sentence debate was (rightly or wrongly) tangled up with the question of realism. There is no explicit statement about truth in the Aufbau, but one wonders what Carnap thought about it at that time. A correspondence theory (as it was commonly understood) seems incompatible with the Aufbau, simply because one relatum is per definition not a constituted object.

${ }^{32}$ The role of the Aufbau as background to the protocol-sentence debate is stressed particularly in Uebel (2007).
} 
number of merely outlined premises. ${ }^{33}$ Nevertheless, the demand for an explication of an (absolute) concept of reality cannot simply be skipped over. As long as this demand is not fulfilled, a criticism of the Aufbau's conception, like the one given here, is strictly speaking the demand for something in the nature of "I don't know what" and, in this sense, question-begging.

\section{References}

Ayer, A.J. 1936. Language, truth and logic. Repr. of the 2nd ed. (1946). New York: Dover, 1952. 1936/37. Verification and experience. Repr. in Ayer 1959, 228-243.

, ed. 1959. Logical positivism. New York: Free Press.

1982. The Vienna circle. Repr. in Ayer, A.J., Freedom and morality and other essays, Oxford: Clarendon Press, 1983, 159-177.

Carnap, R. 1927. Eigentliche und uneigentliche Begriffe. Symposion 1:355-374.

1928a/2003. Der logische Aufbau der Welt. Trans. The logical structure of the world. Chicago/La Salle: Open Court.

— 1928b/2003. Scheinprobleme in der Philosophie. Repr. in Carnap, R., Scheinprobleme in der Philosophie und andere metaphysikkritische Schriften, Hamburg: Meiner 2004, 3-48. Trans. Pseudoproblems in philosophy, in trans. of Carnap, R., Der logische Aufbau der Welt, 301-343.

. 1930/1959. Die alte und die neue Logik. Trans. The old and the new logic, in Ayer 1959, 133-146.

. 1932a/1959. Überwindung der Metaphysik durch logische Analyse der Sprache. Trans.

The elimination of metaphysics through logical analysis of language, in Ayer 1959, 60-81.

1932b. Erwiderung auf die vorstehenden Aufsätze von E. Zilsel und K. Duncker. Erkenntnis 3(2/3): 177-188.

1932c. Über Protokollsätze. Erkenntnis 3(2/3): 215-228.

1936/37. Testability and meaning. Part I: Philosophy of Science 3(4): 419-471; Part II:

Philosophy of Science 4(1): 1-40.

- 1950. Empiricism, semantics, and ontology. Repr. in Carnap, R., Meaning and necessity: A study in semantics and modal logic, 2nd ed. Chicago: University of Chicago Press 1956, 203-221.

1956. The methodological character of theoretical concepts. In The foundations of science and the concepts of psychology and psychoanalysis, = Minnesota studies in the philosophy of science 1, ed. H. Feigl and M. Scriven. Minneapolis: University of Minnesota Press, 38-76.

1963. Intellectual autobiography. In The philosophy of Rudolf Carnap, = Library of living philosophers XI, ed. P.A. Schilpp. LaSalle/London: Open Court/Cambridge University Press, 3-84.

Coffa, A. 1991. The semantic tradition from Kant to Carnap. To the Vienna station, ed. L. Wessels. Cambridge: Cambridge University Press.

Friedl, J. 2013. Konsequenter Empirismus. Die Entwicklung von Moritz Schlicks Erkenntnistheorie im Wiener Kreis, = Moritz Schlick Studien 3. Wien/New York: Springer.

Friedman, M. 1987. Carnap's Aufbau reconsidered. Repr. in Friedman, M., Reconsidering logical positivism, Cambridge: Cambridge University Press 1999, 89-113.

2007. The Aufbau and the rejection of metaphysics. In The Cambridge companion to

Carnap, ed. M. Friedman and R. Creath. Cambridge: Cambridge University Press, 129-152.

\footnotetext{
${ }^{33}$ Coffa $(1991,226)$ speaks (rightly, in my mind) of "careless treatment of this crucial matter" when discussing that section.
} 
Haller, R. 1993. Neopositivismus: Eine historische Einführung in die Philosophie des Wiener Kreises. Darmstadt: Wissenschaftliche Buchgesellschaft.

Mormann, T. 2000. Rudolf Carnap. München: C. H. Beck.

Neuber, M. 2018. Der Realismus im logischen Empirismus. Eine Studie zur Geschichte der Wissenschaftsphilosophie, Veröffentlichungen des Instituts Wiener Kreis. Cham: Springer.

Neurath, O. 1931/1959. Soziologie im Physikalismus. Trans. Sociology and physicalism, in Ayer 1959, 282-317.

Parrini, P. 1994. With Carnap, beyond Carnap: Metaphysics, science, and the realism/instrumentalism controversy. In Logic, language, and the structure of scientific theories: Proceedings of the Carnap-Reichenbach centennial, University of Konstanz, 21-24 May 1991, ed. W. Salmon and G. Wolters. Konstanz/Pittsburgh: Konstanzer Universitäts-Verlag/University of Pittsburgh Press, 255-277.

Richardson, A. 1992. Metaphysics and idealism in the Aufbau. Grazer Philosophische Studien 43:45-72.

1998. Carnap's construction of the world. The Aufbau and the emergence of logical empiricism. Cambridge: Cambridge University Press.

Sauer, W. 1989. Carnap 1928-1932. In Traditionen und Perspektiven der analytischen Philosophie. Festschrift für Rudolf Haller, ed. W.L. Gombocz, H. Rutte, and W. Sauer. Wien: HölderPichler-Tempsky, 173-186.

—. 1992/93. Carnaps Verwerfung der Metaphysik. Conceptus XXVI (68/69): 149-172.

Schlick, M. 1932. Positivismus und Realismus. Trans. Positivism and realism, in Ayer 1959, 82-107.

- 1938/2012. Form and content. In Schlick, M., Erkenntnistheoretische Schriften 1926-1936, ed. u. eingel. v. J. Friedl u. H. Rutte, = Moritz Schlick Gesamtausgabe Abt II, Bd. 1.2. Wien/New York: Springer, 169-358.

Soames, S. 2018. The analytic tradition in philosophy, vol. 2: A new vision. Princeton/Oxford: Princeton University Press.

Uebel, T. 2007. Empiricism at the crossroads. The Vienna circle's protocol-sentence debate. Chicago/LaSalle: Open Court.

Zilsel, E. 1932. Bemerkungen zur Wissenschaftslogik. Erkenntnis 3(2/3): 143-161.

Open Access This chapter is licensed under the terms of the Creative Commons Attribution 4.0 International License (http://creativecommons.org/licenses/by/4.0/), which permits use, sharing, adaptation, distribution and reproduction in any medium or format, as long as you give appropriate credit to the original author(s) and the source, provide a link to the Creative Commons license and indicate if changes were made.

The images or other third party material in this chapter are included in the chapter's Creative Commons license, unless indicated otherwise in a credit line to the material. If material is not included in the chapter's Creative Commons license and your intended use is not permitted by statutory regulation or exceeds the permitted use, you will need to obtain permission directly from the copyright holder.

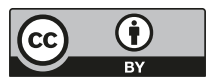

